\title{
Empirical investigations of a reconceptualized personal space
}

\author{
NANCY L. ASHTON \\ Stockton State College, Pomona, New Jersey 08240 \\ and \\ MARVIN E. SHAW \\ University of Florida, Gainesville, Florida 32611
}

\begin{abstract}
Personal space has usually been defined as an area around a person's body that is regarded as personal and private. It is assumed to contract or expand with changing circumstances. It was suggested that this view of personal space has led to (or perhaps derived from) an exclusive concern for negative, defensive reactions to the proximity of others. An alternative conceptualization of personal space was proposed that defines personal space as that area around a person's body in which the presence of others evokes affective reactions (not necessarily negative). The results of three experiments generally support the alternative view of personal space.
\end{abstract}

The way people use physical space and how they react to invasions of space around their bodies has important implications for social behavior. Consequently, research on "personal space" and interpersonal distance has mushroomed and has provided a variety of empirical data, most of which suggest that norms and preferences for interpersonal distance depend upon the situation and the particular people involved (e.g., Argyle \& Dean, 1965; Fisher \& Byrne, 1975; Little, 1965; Sommer, 1969; Willis, 1966). Given the diversity of results reported, especially instances of inconsistency and variability of personal space, it behooves us to examine the concept of personal space more carefully.

Hayduk (1978) notes that the answer to "what is personal space?" has been provided largely by definition. The most common definition is that proposed by Sommer (1969, p. 26): "Personal space refers to an area with invisible boundaries surrounding a person's body into which intruders may not come." Thus conceived, personal space is the space that a person regards as private and defends against invasion by others. It expands or contracts with circumstances and sometimes disappears altogether. This conception of personal space is essentially that proposed or adopted by several other researchers (e.g., Dosey \& Meisels, 1969; Evans \& Howard, 1973; Kinzel, 1970; Little, 1965; Stratton, Tekippe, \& Flick, 1973).

This conceptualization of personal space has led to an almost exclusive concern for negative reactions to the proximity of others. This is evidenced by the kinds of instructions that are used in studies of personal space. In most studies, one person is asked to approach another "as close as is comfortable" or until "you reach a comfortable distance" from the other person (e.g.,
Argyle \& Dean, 1965; Meisels \& Dosey, 1971; Stratton et al., 1973). The view of personal space in terms of negative reactions to the approach of others, and the consequent use of standard "comfortable distance" measures, is one possible reason for the variability of measured personal space across situations and stimulus persons. Persons do not generally display as much discomfort when they approach friends as when they approach strangers, and in many cases interpersonal "intrusion" close to one's body is welcomed. In short, the failure to consider favorable (positive) responses to the approach of others may have introduced an artifact into experimental procedures that resulted in an invalid conception of personal space.

An alternative conceptualization views personal space as the area around a person's body in which the presence of another evokes an affective response (Shaw, 1976). This affective response may be highly positive, as when a loved one approaches, or highly negative, as when a hated enemy approaches. The boundaries of the personal space, however, may be relatively fixed in relation to the person's body. If so, it is not the size of the personal space that varies with the situation or with the relationship between persons, but the affective reaction to the presence of others.

The three experiments discussed in this paper address the issue of the validity of alternative conceptualizations of personal space. The general hypothesis is that people do not feel that they have an exclusive right to the physical space around their bodies and that interpersonal distances will be more consistent across situations if the comfort concept is removed from the instructions to subjects. The three experiments reported below employed two versions of instructions: the standard "comfortable 
distance" instructions and a modified version designed to identify the point at which either a positive or a negative reaction occurs rather than merely the points of discomfort. Thus, there is a direct empirical comparison between setting the personal boundary at the point of discomfort and setting it at the point at which any affective response is evoked.

\section{EXPERIMENT 1}

The purpose of the first experiment was to test the hypothesis that variations in personal space as a function of sex and of interpersonal relationship are artifacts resulting from the usual instruction to "approach as close as is comfortable." For instance, when standard instructions are employed, it has been observed that friends approach more closely than strangers (Little, 1965), and there is some suggestion (not quite significant) that females approach more closely than males (Stratton et al., 1973). It was expected that such variations in size of personal space would not be observed if instructions permitted positive as well as negative responses to the approach of others.

\section{Method}

Forty male and 40 female undergraduate students in introductory psychology classes received credit for participating in the experiment. A mixed-factorial design varied instructions (standard and modified) and sex of subject in the betweensubjects portion of the study. The 2 by 3 within-subjects repeated-measures portion varied sex of simulated stimulus persons and their relationship to the subject (friend, relative, and stranger). Measures of interpersonal distances were obtained by a paper-and-pencil simulation procedure (see Duke $\&$ Nowicki, 1972).

Half of the subjects of each sex were given standard "comfortable approach" instructions, and half were given modified instructions. The standard instructions informed subjects that the sheet of paper before them represented a large room. Each person was asked to assume that he or she was standing in the center of the room and that various persons were entering the room through doors identified by the letters A-F. The entering people were identified as female friend, female relative, female stranger, male friend, male relative, and male stranger. (The positions of stimulus persons were randomly placed for each subject, with the distance between subject and each stimulus person $=5.08 \mathrm{~cm}$.) The subject was asked to take a pencil and draw a line to the point at which "you begin to feel uncomfortable and would want each person to stop." The modified instructions were identical, except that subjects were to draw a line to the point at which "you begin to react to their presence in any way, whether it is a positive or negative feeling."

\section{Results and Discussion}

A five-way analysis of variance was conducted on the pencil-and-paper responses. Only two main effects were significant: instructions $[\mathrm{F}(1,72)=38.37, \mathrm{p}<.01]$ and sex of stimulus person $[\mathrm{F}(1,72)=8.14, \mathrm{p}<.01]$. Standard instructions elicited smaller distances (mean $=$ $.52 \mathrm{~cm}$ ) than did modified instructions (mean $=1.16 \mathrm{~cm}$ ), and female stimulus persons elicited smaller distances $($ mean $=.76 \mathrm{~cm})$ than did males $($ mean $=.91 \mathrm{~cm})$. Sex of subject approached significance $[F(1,72)=2.99$, $\mathrm{p}<.10$ ] (mean $=.93 \mathrm{~cm}$ for males and $.75 \mathrm{~cm}$ for females).

The Instructions by Relationship interaction (which is a test of the major hypothesis) reached significance $[F(2,144)=8.50, p<.01]$. Newman-Keuls tests showed that all means differed at the .01 level except for the relative and friend standard, which did not differ, and the three means for modified instructions, which did not differ from each other. Thus the hypothesis that the modified instructions would yield more constant interpersonal distances than the comfort version received some support; none of the three means for modified instructions differed, and the "stranger" mean under standard instructions did differ from the other two means. For the variables of sex of subject and sex of stimulus person, the hypothesis was not confirmed. However, standard instructions typically yield small, often nonsignificant, sex differences (Stratton et al., 1973).

\section{EXPERIMENT 2}

The purpose of Experiment 2 was to test the hypothesis by obtaining a behavioral measure of interpersonal distance under standard and modified instructions. This experiment also varied sex of subject, sex of stimulus person, relationship, and the additional variable of direction of approach. It was expected that with standard instructions females would approach more closely than males and friends more closely than strangers and that the closest approach would be from the back and the most distant, from the front. These variations were not expected to occur with modified instructions.

\section{Method}

Forty female and 40 male students in introductory psychology received course credit for their participation in the experiment. A 2 by 2 by 2 by 3 mixed-factorial design varied the relationship between subject and stimulus person (friend or stranger), sex of subject, form of instructions (standard or modified), and approach direction (front, side, and back).

The stimulus person for each subject was either a same-sex undergraduate stranger or a same-sex friend that the subject brought with him or her. The subject was told to walk slowly toward the other person and either "stop when you start to feel uncomfortable" (standard instructions) or "stop at the point where you react to the proximity of you two in any way" (modified instructions). Subjects walked toward the stimulus person from three approach angles (front, side, and back), in randomized order. The experimenter recorded the distance between the two persons when the subject stopped.

\section{Results and Discussion}

An analysis of variance with repeated measures was conducted with form of instructions, sex of subject, relationship of subject to stimulus person, and approach direction as independent variables. (An additional analysis of variance with order of the three approaches as an independent variable showed that order had no 
effect.) As with Experiment 1, form of instructions had a significant effect $[F(1,72)=15.65, p<.01]$, with modified instructions eliciting a larger distance $($ mean $=$ $49.6 \mathrm{~cm}$ ) than standard instructions (mean $=25.6 \mathrm{~cm}$ ). The other main effect was for position of approach $[\mathrm{F}(2,144)=8.39, \mathrm{p}<.01]$, with front $($ mean $=45.8 \mathrm{~cm})$ distance greater than side $($ mean $=34.7 \mathrm{~cm})$, which in turn was greater than back (mean $=32.2 \mathrm{~cm})$.

The interaction effect of Instructions by Relationships was significant $[F(:, 72)=5.38, p<.05]$. A test of pairwise comparisons showed that the only significant difference $(p<.05)$ was between standard friend $($ mean $=20.7 \mathrm{~cm})$ and modified friend $($ mean $=58.7 \mathrm{~cm})$. Thus, under neither standard nor modified instructions did subjects differ in the distance to friend and stranger. This result with standard instructions is not consistent with the hypothesis. However, the finding that modified instructions yielded a greater distance than standard instructions for friends suggests that persons have an affective reaction to the proximity of friends sooner than indicated by the "comfortable distance" instructions.

\section{EXPERIMENT 3}

Experiment 3 was conducted to determine whether interpersonal distances are affected by explicit communication of the criteria that subjects were expected to use in reacting to the proximity of another person. In addition, the subject was asked to react to the approach of another person by telling that person when to stop, rather than approaching and deciding when to stop, as in Experiment 2.

\section{Method}

Thirty-two undergraduates served as subjects with 32 undergraduate stimulus persons. A 2 by 2 factorial design varied instructions (standard or modified) and relationship (friend or stranger). Front or side approaches constituted a repeatedmeasures portion of the design.

Subjects participated with either a same-sex stranger or a same-sex friend that they had been asked to bring with them. All subjects were given a brief, but concise, statement about the concept of personal space and about some of the reactions that approach of another elicits. Subjects assigned to the standardinstructions condition were told that intrusion into the area near a person's body is often assumed to elicit negative reactions, such as anger and discomfort. They were also told that when the other person approached, they were to say "stop" at the point at which one more step would cause the other person to be within the space that was regarded as a comfortable distance from him/her. Subjects in the modified-instructions condition were told that the nature of responses to the approach of another person may depend upon such things as who is approaching, the situation, and one's own characteristics, and that reactions might sometimes be positive. They were told to say "stop" when they felt they had a right to do so, whether or not it felt comfortable.

The initial distance between the two persons was $6.09 \mathrm{~m}$. The experimenter recorded the distance between them when the subject said "stop" for both front and side approach.

\section{Results and Discussion}

In contrast with the results of preceding studies, modified instructions yielded closer approach distances $($ mean $=33.96 \mathrm{~cm})$ than did standard instructions $($ mean $=50.79 \mathrm{~cm}) \quad[\mathrm{F}(1,28)=4.99, \mathrm{p}<.05] . \quad$ Consistent with previous findings, the approach variable also was significant $[F(1,28)=6.56, p<.05]$, with front approach producing greater interpersonal distances $($ mean $=49.20 \mathrm{~cm}$ ) than side approach (mean $=$ $35.55 \mathrm{~cm}$ ). As in Experiment 2, there was no difference in the approach of friend vs. stranger, and interactions were nonsignificant.

The major aspect of the modified instructions was that the subject was asked to tell the other person to stop whenever he or she felt that the other person was in his or her personal private space. Under these conditions, the subject apparently believed that a smaller area is private than is usually found with standard instructions. That is, individuals feel uncomfortable before they believe they have the right to tell others to stop.

\section{GENERAL DISCUSSION}

Taken together, the results of these experiments provide little support for the traditional conceptualization of personal space as a private area that expands or contracts with circumstances. Although the data indicate that the distance between a person and another person elicits varying reactions that may be favorable, indifferent, or unfavorable, there is little evidence that persons believe they own or have exclusive right to the physical space surrounding their bodies. The results of the first experiment are consistent with the view that personal space is the area around a person's body in which the presence of another person evokes an affective response (Shaw, 1976). The results also support the expectation that the boundaries of this area are relatively fixed in relation to the person's body, since the usual variations as a function of interpersonal relationship did not occur.

The results of the second experiment are partially consistent with the affective-reaction conceptualization, and they were not in accord with the traditional conception of personal space. That is, persons who were instructed to stop when they had any reaction to the proximity to the other person stopped further away than those persons given standard "comfortable approach" instructions, a finding that indicates that affective reactions occur at greater distances than indicated by traditional research.

Finally, the data from Experiment 3 indicate quite clearly that people do not believe they have a right to tell others not to enter the physical area near their bodies. Instructions to tell the other person to stop "when you feel you have a right to do so" yielded very small interpersonal distances (approximately $1 \mathrm{ft}$ ). In fact, if the subject had not said "stop" when he or she did, one more step by the stimulus person would have resulted in body contact.

In conclusion, the data from the three experiments reported here are consistent with the conceptualization of personal space as that area around a person's body in which the presence of another person evokes an affective response, and they are quite inconsistent with the notion of personal space as an area that is regarded as personal and private. Recognition of the fact that persons do not believe they have exclusive rights to the space around them and the fact that reactions to "intrusion" may not always be negative should encourage a more complete analysis of interpersonal distance efforts. 


\section{REFERENCES}

Argyle, M., \& Dean, J. Eye contact, distance and affiliation. Sociometry, 1965, 28, 289-304.

Dosey, M. A., \& Meisels, M. Personal space and self-protection. Journal of Personality and Social Psychology, 1969, 11, 93-97.

Duke, M. P., \& Nowicki, S. A new measure and social-learning model for interpersonal distance. Journal of Experimental Research in Personality, 1972, 6, 1-16.

Evans, G. W., \& Howard, R. B. Personal space. Psychological Bulletin, 1973, 80, 334-344.

Fisher, J. D., \& Byrne, D. Too close for comfort: Sex differences in response to invasions of personal space. Journal of Personality and Social Psychology, 1975, 32, 15-21.

Hayduk, L. A. Personal space: An evaluative and orienting overview. Psychological Bulletin, 1978, 85, 117-134.

Kinzel, A. F. Body buffer zone in violent prisoners. American
Journal of Psychiatry, 1970, 127, 59-64.

LitTle, K. B. Personal space. Journal of Experimental Social Psychology, 1965, 1, 237-247.

Meisels, M., \& Dosey, M. A. Personal space, anger arousal, and psychological defense. Journal of Personality, 1971, 39, 333-344.

Shaw, M. E. Group dynamics: The psychology of small group behavior (2nd ed.). New York: McGraw-Hill, 1976.

Sommer, R. Personal space: The behavioral basis of design. Englewood Cliffs, N.J: Prentice-Hall, 1969.

Stratton, L. O., Tekippe, D. J., \& Flick, G. L. Personal space and self-concept. Sociometry, 1973, 36, 424-429.

Willis, F. N., JR. Initial speaking distance as a function of the speakers' relationship. Psychonomic Science, 1966, 5, 221-222.

(Received for publication March 8, 1980.) 